\title{
OLIVEIRA, Romualdo Portela e SANTANA, Wagner (orgs). Educação e federalismo no Brasil: combater as desigualdades, garantir a diversidade. Brasília: Unesco, 2010.
}

\section{Por Isabelle Fiorelli Silva}

A presente obra deflagra assertivamente o "nó górdio" da política educacional brasileira, desvelando suas contradições e perspectivas sob o prisma do federalismo. Chama a atenção dos pesquisadores na área e dos gestores públicos para a necessidade de compreendê-la, sob o ângulo do federalismo, denunciando seus principais mecanismos, entraves e possibilidades para a efetivação do direito à educação. Trata-se, nessa obra, de salientar a questão federativa e seus aspectos políticos e institucionais, no que diz respeito à garantia do direito à educação em meio a um Sistema Nacional de Educação a ser constituído na política educacional brasileira.

$\mathrm{Na}$ introdução Romualdo Portela de Oliveira e Sandra Zákia de Souza traçam um panorama hostórico-político-legal da evolução da garantia ao direito à educação no contexto da federação brasileira, considerando como elementos inerentes historicamente constituídos, tanto a desigualdade de condições econômicas e distribuição de competências entre os entes federados, quanto a tensão entre centralização e descentralização. O marco de suas análises vai da Lei Geral de 1827 até chegar à legislação atualmente vigente (CF de 1988, LDB 9.394/96, Lei n. ${ }^{\circ}$ 9.424/96, PNE de 2001, etc.), inclusive seus programas de governo, delineando as possibilidades e os limites para o regime de colaboração entre os entes federados na política educacional brasileira. Além disso, destaca o papel equalizador da União nesse regime, frente à impossibilidade de reforma tributária estrutural que combata fatalmente a desigualdade, na garantia do direito à educação, sinalizando seus principais problemas com o apontamento de formas para equacioná-los como: 1) buscar aperfeiçoar o arranjo já existente, 2) implantar mecanismos de financiamento que visem alinhar oferta de serviços com recebimento de recursos e, 3) utilizar a capacidade da esfera federal, induzindo outros entes a pactuarem proposições de interesse comum, no caso a democratização da educação.

Fernando Luiz Abrucio é o autor do primeiro capítulo: A dinâmica federativa da educação brasileira: diagnóstico e propostas de aperfeiçoamento. Nele analisa o impacto do federalismo no funcionamento da educação do país, explicitando suas características, desde a independência em 1822 até sua configuração atual, mostrando como o peculiar federalismo brasileiro vem se constituindo e afetando as políticas públicas. Deflagra "os dilemas para implementar políticas descentralizadas num país bastante heterogêneo, desigual e marcado por significativas tensões intergovernamentais" (ABRÚCIO, 2010, p. 39). Reconhece que os últimos anos foram marcados pela criação de programas direcionados aos municípios, entretanto, considera relevante tanto a ativação de arenas intergovernamentais que conjuguemcooperaçõesarticuladasecolaborativas, quanto a perseguição pela combinação da descentralização com diretrizes nacionais. Ressalta que, para o sucesso da forma de Estado federativo, são necessárias a compatibilização entre autonomia e interdependência entre os entes, a redução das assimetrias socieconômicas entre as esferas governamentais e a instituição de arenas institucionais que garantam a representação, a negociação e o controle das políticas públicas. Anuncia a falta de clareza existente na legislação vigente sobre a repartição de responsabilidade 
entre os entes, gerando competição entre os níveis de governo e, consequentemente, instaurando um "federalismo compartimentalizado" (ABRÚCIO, 2005 apud ABRÚCIO, 2010). É altamente elucidativo o quadro que esboça o jogo de poder federativo influente na definição da política educacional quanto aos mecanismos de gestão e financiamento amparados legalmente, ao concluir que a formação de um Sistema Nacional de Educação deveria ser orientada por uma política redistributiva de recursos, para além da política equalizadora do Fundef e Fundeb, pelo fortalecimento da gestão municipal, pelo aumento da cooperação entre os entes federados e pelo funcionamento de Fóruns federativos rumo à utilização literal do novo Plano Nacional de Educação.

O segundo capítulo: Federalismo fiscal: em busca de um novo modelo, escrito por Fernando Rezende, aborda uma das questões centrais em qualquer regime federativo, qual seja, a repartição fiscal entre os entes federados. O principal desafio apontado é a busca por uma capacidade de financiamento compatível com as respectivas responsabilidades dos entes federados, dadas as disparidades e desigualdades regionais e sociais que agravam o desequilíbrio federativo. Anuncia a adoção de um regime de equalização fiscal que garanta aos estados e municípios, mediante a transferência de recursos da federação, um orçamento capaz de assegurar o funcionamento de suas responsabilidades básicas. Considera exitosa a adoção do Fundef na sua capacidade de redistribuição interestadual dos recursos vinculados à educação, de forma que, segundo Rezende, acaba por aproximar a demanda por matrículas escolares aos recursos disponíveis, proporcionando potencial eficiência da política, apesar de se limitar na redistribuição no interior de cada estado. Além disso, assim como Abrúcio, denuncia a necessidade de promoção da cooperação intergovernamental no financiamento e na gestão das políticas públicas, eliminando a guerra fiscal fomentada pelos estados e municípios na repartição dos recursos da União. Nesse sentido, esclarece que a "ausência de vínculo entre o regime de garantias sociais e o federalismo fiscal contribui para a redução de sua eficácia (...)" (REZENDE, 2010, p. 81).
No terceiro capítulo: A gestão do Sistema Único

de Saúde, Jurandi Frutuoso apresenta a estrutura do SUS como possibilidade de organização na área das políticas sociais, na garantia de um direito no contexto do Estado federativo brasileiro. O leitor tomará conhecimento do processo de constituição do sistema nacional de saúde, desde a imersão da consciência sanitarista no século XX até sua recente configuração, de seus desafios e avanços. Quanto a este aponta, entre outros aspectos, a gestão colegiada instada por meio de conselhos e instâncias de controle social, além dos mecanismos de transferência fundo a fundo, de forma regular e automática, da União para municípios, estados e Distrito Federal.

Ademais, considera que o SUS aproxima-se de uma experiência de federalismo cooperativo, podendo servir de base de referência para a formulação de outros sistemas, no caso, o Sistema Nacional de Educação. Quanto aos desafios, permanece o entrave da necessidade de superação do atendimento desigual desencadeado pela diversidade regional e cultural e a constante perseguição da melhoria da qualidade dos serviços públicos da saúde.

Alejandro Morduchowies e Aída Arango são os autores do quarto capítulo da obra em questão. Sob o título "Desenho institucional e articulação do federalismo educativo: experiências internacionais" esboçam a organização política adotada por nações cujas formas de Estado se assentam no federalismo, assim como arquitetam institucionalmente seus sistemas educacionais. Também está presente em sua análise a tensão entre centralização e descentralização no funcionamento da federação, sugerindo que se deva dar ao nível local maior capacidade de decisão no planejamento, na execução e avaliação da educação e a adoção de cooperação intergovernamentalnacoordenaçãoeimplantação de projetos e programas conjuntos.

O debate acerca do regime de colaboração em educação, no contexto federativo, a partir de uma perspectiva histórico-política, é discorrido por Carlos Jamil Cury, no quinto capítulo: A questão federativa e a educação escolar. Aborda claramente o significado epistemológico, político e histórico do federalismo enquanto tipo específico de Estado. No 
Brasil, destaca sua evolução desde a proclamação da República Federativa Brasileira até à Carta Magna vigente, explicitando as idas e vindas entre federalismo centrípeto (centralizado) e federalismo centrífugo (descentralizado) na constituição de seu sistema federativo. Demonstra que apesar da opção pelo federalismo cooperativo, que exigiria entendimento mútuo e colaboração recíproca (CURY, 2010), ainda está por se regulamentar tal regime colaborativo entre os entes federados para viabilizar a efetivação de um Sistema Nacional de Educação e, consequentemente, da garantia do direito à educação. Nesse campo, salienta o amparo legal do pacto federativo, defendendo a orientação por um Sistema Nacional de Educação articulado e cooperativo.

A dinâmica recente do financiamento da educação, seus limites e contradições, é a temática central do sexto capítulo do livro, redigida por Jorge Abraão de Castro, mostrando a aplicação e movimentaçãodosrecursospúblicosnoatendimento das necessidades e demandas por bens e serviços educacionais. A discussão acerca da necessidade de ampliação do acesso na educação infantil, no ensino médio e superior, e da melhoria da qualidade dos serviços públicos educacionais, insere-se na agenda de debate do autor, sendo desafios recentes a serem superados no atual contexto da política educacional brasileira. Num primeiro momento, são apresentados categoricamente os elementos que compõem a estrutura de competências e responsabilidades no financiamento da educação e a estratégia de subvinculações (Fundef) e, num segundo momento, analisa os resultados obtidos de 1995 a 2007 em termos de gasto público educacional. Nesse segundo caso, deflagra um crescimento inconstante, mas real, do gasto em termos per capita em educação. Entretanto, para o autor, tal crescimento se explica muito mais pelo crescimento do PIB no país, e consequentemente da receita tributária, do que pelo benefício de maior aporte de recursos para a educação, além dos já garantidos legalmente.

No sétimo capítulo: Participação e regime de colaboração entre unidades federadas na educação brasileira, a autora, Elie Ghanem, problematiza os condicionantes à participação da população na sociedade e, mais especificamente, no sistema educacional. Coloca como visceral o papel do Estado no cumprimento da garantia constitucional de direito à educação e a exigência da partilha de decisões entre as unidades federadas e da participação da população em conselhos ou afins na busca por assegurar um atendimento de qualidade desse direito.

As experiências dos estados brasileiros, explicitadas nos capítulos subsequentes, permitem-nos elaborar propostas que viabilizem a constituição de um Sistema Nacional de Educação que, com base num regime de colaboração regulamentado e criterioso, demonstre efetiva articulação entre os entes federados e seus sistemas de ensino no cumprimento legal de igualdade de condições de acesso, permanência e sucesso escolar. Nesse sentido, no livro encontra-se o relato de experiências recentes de colaboração entre sistemas, do Mato Grosso, do Rio Grande do Sul e do Ceará.

No oitavo capítulo: Federalismo cooperativo e educação brasileira: a experiência de Mato Grosso (com a) proposição de um sistema único de educação, Carlos Abicalil e Odorico Ferreira Cardoso Neto fazem um relato das experiências realizadas no estado do Mato Grosso, considerando-se este como único estado brasileiro a contemplar em sua Constituição Estadual o estabelecimento de um Sistema Único de Educação. Os autores detalham o processo de amadurecimento da proposta de sistema único de educação no estado, imerso num contexto profícuo de construção coletiva em torno de interesses comuns. Evidenciam que, embora o estado tenha tido "ensaios" quanto a unificações de políticas e programas educacionais, exemplificados na criação de Fundação e no estabelecimento de convênios, exige-se, contudo, a definição de critérios mais transparentes na gestão dos recursos disponíveis e o cumprimento efetivo da legislação nacional e estadual.

No Rio Grande do Sul, Maria Beatriz Luce e Marisa Timm Sari descrevem a constituição de cooperações intergovernamentais de estado com municípios e de municípios entre municípios. Apresentam um clima bastante propício para o estabelecimento do regime de colaboração, por meio da instituição de 
alguns mecanismos constituídos histórica e coletivamente no estado do Rio Grande do Sul. A organização de associações microrregionais na definição de políticas comuns, a articulação entre Conseme/Undime-RS e outras entidades representativas, o ordenamento legal do regime de colaboração resultante de negociações entre estado e municípios, entre outros mecanismos de cooperações intergovernamentais se fizeram presentes e se delinearam no interior do estado nas últimas décadas. Apontam que apesar desse potencial gaúcho de fomentar o fortalecimento do regime de colaboração, por sua tradição política histórica, ainda há limites a serem superados, pois, para as autoras, o regime de colaboração federativo é uma estratégia que se constrói a cada dia (LUCE e SARI, 2010, p. 265). Conclui-se que se faz latente a constituição e a regulação de relações cooperativas entre os entes federados para a efetiva viabilização de uma educação pública de qualidade para todos.

A colaboração entre o estado do Ceará e seus municípios é abordada no texto de Sofia Lerche Vieira, no último capítulo: Educação básica no Ceará: construindo um pacto colaborativo. A experiência do Ceará, relatada por Vieira, apresenta características semelhantes à experiência do Rio Grande do Sul, dadas as suas aproximações quanto à tradição de participação e a criação de grupo de trabalho para tratar do regime de colaboração no interior do estado, prevendo formas diferentes de cooperação técnica e financeira. Além disso, os dois estados criaram órgãos colegiados regionais e locais e convênios intermunicipais nas mais diversas ordens na busca pela efetivação do regime de colaboração.
As dificuldades oriundas da experiência cearense vão em direção à sobrecarga técnica e financeira que receberam os municípios, à sua cultura patrimonial e clientelista no jogo de interesses políticos e a abstenção da sociedade civil nesse processo (VIEIRA, 2010, p. 284).

Concluindo, sob o rol de reflexões tecidas por Romulado Portela de Oliveira e Sandra Zákia de Souza, ressaltam-se os dilemas e impasses para a materialização de uma concepção de Sistema Nacional de Educação no Brasil. A tensão entre centralização e descentralização no arranjo federativo, a composição justaposta dos conselhos estaduais e municipais que dialogam deficitariamente, o estabelecimento de uma política redistributiva, de recursos capazes de reduzir as disparidades e desigualdades regionais e locais, e a cooperação técnica e financeira regulamentada entre os entes federados, configurando um efetivo regime de colaboração na federação brasileira quanto ao provimento educacional. Tais aspectos foram deflagrados no conjunto de textos do livro em questão e evidenciados por Oliveira e Souza (2010) nas considerações finais da obra, na qual buscaram captar os aspectos cruciais do debate atual da política educacional brasileira, localizado no pacto federativo para o provimento educacional.

Contudo, segundo os autores, os textos evidenciam a necessidade de uma estrutura político-jurídico-institucional capaz de concretizar a dinâmica federativa no provimento da educação, tendo em conta as desigualdades entre os entes federados do país. Por isso, a leitura dessa obra se faz obrigatória para aqueles que se propuserem a compreender profundamente a política educacional brasileira. 